\title{
Hypofractionated simultaneous integrated boost (IMRT-SIB) with pelvic nodal irradiation and concurrent androgen deprivation therapy for high-risk prostate cancer: results of a prospective phase II trial
}

\author{
Alessandro Magli ${ }^{1} \cdot$ Eugenia Moretti ${ }^{2} \cdot$ Annarita Tullio $^{3} \cdot$ Gianluca Giannarini $^{4} \cdot$ Fabrizio Tonetto $^{5} \cdot$ Mauro Urpis $^{1}$. \\ Margherita Crespi ${ }^{2}$. Claudio Foti ${ }^{2} \cdot$ Agnese Prisco $^{1} \cdot$ Margherita Polsinelli $^{1} \cdot$ Gioacchino De Giorgi ${ }^{4}$. \\ Giulia Bravo $\mathbb{D}^{6} \cdot$ Paolo Scalchi $^{2} \cdot$ Marco Trovò $^{1}$
}

Received: 25 September 2017 / Revised: 9 November 2017 / Accepted: 23 December 2017 / Published online: 8 March 2018

(c) The Author(s) 2018. This article is published with open access

\begin{abstract}
Objective The approach for treating high-risk prostate cancer still presents different unresolved issues. We report the safety and efficacy of a radiation therapy strategy based on the combination of moderate hypofractioned simultaneous integrated boost (SIB) and Image Guidance.

Materials and methods In this phase II trial of patients with high-risk prostate cancer, Image Guided SIB-IMRT plans (Simultaneous Intensity Modulated - Intensity Modulated Radiotherapy) were delivered between 2009 and 2012 . All patients enrolled (41) received in 25 fractions a total dose of $67.5 \mathrm{~Gy}$ (2.7 Gy/fraction) to the prostatic volume, $56.25 \mathrm{~Gy}(2.25 \mathrm{~Gy} /$ fraction) to the seminal vescicles, and $50 \mathrm{~Gy}(2.0 \mathrm{~Gy} /$ fraction) to the pelvic lymph nodes (LN) chains with concurrent androgen deprivation therapy (ADT). The image-guided radiotherapy (IGRT) procedure was performed using three gold seeds. RTOG late gastrointestinal and genitourinary toxicities and 6-year biochemical relapse-free survival (BRFS) were assessed in combination of their statistical correlation with clinical factors and dosimetric parameters.

Results Rate of late genitourinary toxicity grade 2 was $9.8 \%$, while rates of late gastrointestinal toxicity were $14.6 \%$ and $2.4 \%$, for grade 1 and 2, respectively. Diabetes and maximum doses to rectum appeared to be statistically relevant risk factors for late rectal toxicity. Five-year BRFS was $95.1 \%$.

Conclusions In our study, we observed positive results in terms of toxicity and good efficacy in a cohort of high-risk prostate cancer patients treated with a multimodality therapy approach comprising hypofractionation, irradiation of pelvic nodes (common iliac nodes included), and concurrent ADT. These favorable results may merit further investigation in a phase III randomized trial to confirm that whole pelvic radiation therapy (WPRT) combined with moderate hypofractionation and ADT could be performed safely and effectively.
\end{abstract}

Electronic supplementary material The online version of this article (https://doi.org/10.1038/s41391-018-0034-0) contains supplementary material, which is available to authorized users.

Alessandro Magli

alessandro.magli@asuiud.sanita.fvg.it

1 Department of Radiation Oncology, University Hospital of Udine, ASUIUD - piazzale S.M della Misericordia 15, 33100 Udine, Italy

2 Department of Medical Physics, University Hospital of Udine, ASUIUD - piazzale S.M della Misericordia 15, 33100 Udine, Italy

3 Institute of Hygiene and Clinical Epidemiology, University Hospital of Udine, ASUIUD - piazzale S.M della Misericordia 15,

\section{Introduction}

Clinically localized high-risk prostate cancer (PCa) is related to a substantial disease recurrence after the

33100 Udine, Italy

4 Department of Urology, University Hospital of Udine, ASUIUD - piazzale S.M della Misericordia 15, 33100 Udine, Italy

5 Department of Radiation Oncology, IOV-IRCCS Padova, Via Gattamelata, 64, 35128 Padova, Italy

6 Department of Medical Area, University of Udine, ASUIUD - piazzale S.M della Misericordia 15, 33100 Udine, Italy 
administration of local treatment with radical intent, regarding more than $50 \%$ of patients within 10 years post treatment $[1,2]$. Due to the unavailability of suitable randomized trials, the more appropriate therapeutic paradigm is still a matter of debate. According to NCCN and EAU guidelines recommendations, the standard of care is represented by external beam radiation therapy (EBRT) associated with long-term androgen deprivation therapy (ADT).

Roach et al. [3] reported the results of the Radiation Therapy Oncology Group 94-13 randomized trial, which proven significantly better progression-free survival for high-risk PCa treated with whole pelvic radiation therapy (WPRT) compared with prostate-only radiation therapy (PORT). In addition, recently emerging evidence [4] supports the use of elective nodal irradiation, with the involvement of the common iliac nodes, to warrant the complete coverage of micrometastatic disease.

The enhanced rate of radiation-related toxicity is the most relevant consequence of adopting WPRT approach. In fact, cute gastrointestinal (GI) and genitourinary (GU) complications were most commonly occurred in patients treated with WPRT than in those receiving PORT $[5,6]$.

On the other side, several planning studies showed [6-11] that through the use of the modulated photon beams (intensity-modulated radiation therapy, IMRT) acute GI [10] and GU [11] were substantially diminished since restricted parts of bladder and rectum received high value of dose.

Moreover, recently clinical investigations have revealed that currently used dose fractionation schemes influence significantly the PSA control $[12,13]$.

It is now largely accepted that PCa has a low alpha/beta ratio (estimated in the range of $1-3 \mathrm{~Gy}[14,15]$ ), which makes hypofractionation theoretically advantageous in producing tumor cell death while reducing late toxicity in healthy tissues.

In our phase II trial, we studied the toxicity and the efficacy of marker-based image-guided (IG) concomitant delivery of different levels of radiation dose within a single treatment fraction (SIB, simultaneous intensity boost) to prostate, vesicles, and whole pelvic nodal chains (including common iliac nodes), combined with ADT.

\section{Materials and methods}

\section{Study design and population}

This was a single-institution prospective phase II clinical trial. The research ethics board of the University Hospital of Udine (ASUIUD) approved the study, and all the patients enrolled signed an informed consensus, according to the Helsinky Declaration.
Eligible patients had histologically confirmed prostate cancer with at least one of the following high-risk features: clinical stage $\mathrm{T} 2 \mathrm{c} / \mathrm{T} 3$ or PSA level $\geq 20$ but $<100 \mathrm{ng} / \mathrm{mL}$ or Gleason score $\geq 8$ [16].

Exclusion criteria comprised lymph nodes involvement, distant metastasis, a history of inflammatory bowel disease, active collagen vascular disease, previous malignancy within 5 years of prostate carcinoma diagnosis (except nonmelanomatous skin cancer), prior pelvic RT, hip prosthesis (which would prevent electronic portal imaging, EPI, of the implanted fiducial markers from a lateral direction), and severe urinary symptoms based on the total IPSS score of 20-35. Elective pelvic nodal treatment was administered according to a proposed $>15 \%$ risk of occult nodal involvement as calculated by the Roach formula [17].

\section{IMRT treatment planning and delivery}

Pre-treatment comprehensive clinical assessment foresaw, staging investigations (whole body bone scan and computed tomography (CT) of the abdomen and pelvis), and blood work (including PSA determination, liver function tests, and testosterone measurement).

Three gold markers for the image-guided radiotherapy (IGRT) procedure were inserted into the prostate under transrectal ultrasound guidance and 20 days before CT scan dedicated for treatment planning. Their size was $1.2 \mathrm{~mm}$ diameter and $3 \mathrm{~mm}$ length. Fiducial markers were used to register treatment confirmation images with the corresponding reference planning images to correct the daily inter-fractional motion.

All patients underwent CT simulation in the supine position after immobilization with COMBIFIX.

CT planning was performed with $0.3 \mathrm{~cm}$ spacing and 0.3 $\mathrm{cm}$ slice thickness from above the L4-L5 interspace through the mid-femur. Patients were instructed to use a Fleet enema the evening before and the morning of the treatment simulation session. All patients underwent CT scanning with an empty rectum and a moderately full bladder. If rectal volume (including filling) exceeded 100 ml, we proceeded with re-scanning. Furthermore, patients were instructed to achieve the same conditions (rectal emptying and bladder "filling"), before each RT delivery session.

The clinical target volume (CTV) relative to the prostate was defined as the whole prostate proximal $1.5 \mathrm{~cm}$ of the seminal vesicles and any visible tumor extension.

The prostate planning target volume (PTV) was generated by adding an isotropic $0.5 \mathrm{~cm}$ margin to the prostate CTV. The CTV elective nodes contoured included those within $0.7 \mathrm{~cm}$ around the pelvic blood vessels and excluded muscle and bone from the volume [18]. The pelvic volume treated in the current study included the common iliac 
lymph nodes as well. Nodal PTV was obtained expanding the CTV nodes in all the directions by a $0.8 \mathrm{~cm}$.

All patients received a total dose of $67.5 \mathrm{~Gy}$ in 25 fractions (2.7 Gy/fraction) to the prostate PTV, at least $56.25 \mathrm{~Gy}$ $(2.25 \mathrm{~Gy} /$ fraction) to the seminal vesicles PTV and $50 \mathrm{~Gy}$ (2.0 Gy/fraction) to the nodal PTV.

Step-and-Shoot IMRT plans (S-S IMRT) consisting in five to seven 6-MV fields were calculated with Oncentra treatment planning system (Oncentra Masterplan ${ }^{\circledR}$, Elekta) and delivered on Varian 600C linear accelerator (Varian Medical Systems).

Regarding the target coverage, the purpose was to ensure that prescribed dose was more than $95 \%$ of the volume of each treatment site (prostate, seminal vesicles, and pelvic lymph nodes). A maximum dose of $107 \%$ of the intended dose was allowed to $<2 \%$ of prostate PTV. For seminal vesicles PTV and pelvic nodes PTV, we accepted a maximum dose of $110 \%$ of the respective dose values. The organs at risk (OARs) considered were: rectum, bladder, intestinal cavity, femoral heads, and penile bulb. We derived the OAR dose constraints based on the conventional 3DCRT planning of our Institute and scaling them through the linear quadratic model, to take into account the unconventional dose fractionation. (The dose constraints are summarized in supplementary Table 1).

During delivery fractions, patients were positioned according to simulation setup and aligned to their three skin tattoos referring to treatment room lasers. To correct the interfraction changes and the treatment setup errors, EPI was taken for daily IGRT. The practiced method involved on-line comparison of an orthogonal EPIs pair with the relative reference planning images (digitally reconstructed radiographs: DRRs) using manual template matching referred to the gold markers. If the resultant discrepancy was greater than $2 \mathrm{~mm}$ but minor than $6 \mathrm{~mm}$ (in any direction), a couch correction shift was performed.

Since prostate could move independently of the vessels, treatment was not delivered when errors resulted greater than $6 \mathrm{~mm}$.

\section{Follow-up}

Once a week during treatment, full blood work, physical examination, and toxicity evaluation were performed.

Following the cessation of radiation therapy, in the first 2 years, patients were monitored with physical exam, urine test, serum PSA, and renal function determination, on a quarterly basis, in the first 2 years, and on a 6-month basis, in the next 3 years; after which, the frequency of checks became annual. Follow-up period took for the patients until last observation or death.
According to the Phoenix definition, biochemical recurrence (BR) was defined, as an increase in the PSA level of $2 \mathrm{ng} / \mathrm{mL}$ or more above the PSA nadir after RT [19]. All patients with BR were treated with continuous ADT.

\section{Study end points}

Primary end point was toxicity. Acute toxicity was defined as any new event occurring during RT or within 3 months after RT, and late toxicity as any event persisting or occurring more than 6 months after RT completion. The degree of toxicity was prospectively recorded using the Radiation Therapy Oncology Group (RTOG) morbidity criteria. The maximal toxicity scores were reported.

To explore the correlation of doses received by normal tissues with toxicity, we considered the final values of the treatment planning parameters.

Secondary end point was efficacy. BRFS was determined from the first day of RT until either the date of the last follow-up or the date of death/relapse.

\section{Statistical analysis}

To determine the sample size, the method of Simon's twostage optimal design was conducted [20]. Our study was planned to evaluate rectal toxicity, considering as acceptable, an acute grade $\geq 2$ toxicity rate of $\leq 5 \%$, and considering as unacceptable with a $90 \%$ power and a significance level of $5 \%$, an acute grade $\geq 2$ toxicity rate of $\geq 25 \%$. The stopping rules laid down by the investigation were: grade $\geq 2$ toxicity in $\geq 1$ patient during the first stage (21 patients) and in $\geq 4$ patients in the second stage ( 41 patients).

Descriptive statistics were performed on categorical and numerical variables. Frequency distributions were used for categorical variables. Kolmogorov-Smirnov test was performed for checking data distribution's normality on numerical variables.

The late toxicity or relapse and its standard error (SE) were estimated with the cumulative incidence function, and differences between groups were analyzed using the homogeneity test developed by Gray. The relationship between clinical and laboratory factors and late toxicity or relapse was evaluated with the Fine and Gray's [21] extension of the Cox regression model. To investigate the potential predictors for late toxicities, several factors were considered: age, diabetes, ADT duration, hypertension, anticoagulation therapy, use of drugs (anti-coagulant, antihypertensive), and dose parameters.

Survival analysis was performed using the cumulative incidence function and Gray's test [22] for testing the homogeneity of two or more cumulative incidence 
Table 1 Patient characteristics $(n=41)$

\begin{tabular}{|c|c|}
\hline Characteristic & Value \\
\hline \multicolumn{2}{|l|}{ Age, yr } \\
\hline Mean \pm DS & $71.83 \pm 6.14$ \\
\hline Median & 72 \\
\hline Range (min-max) & $51-81$ \\
\hline IQR & 6 \\
\hline \multicolumn{2}{|l|}{ Clinical T stage, $N$} \\
\hline $\mathrm{T} 1-\mathrm{T} 2 \mathrm{~b}$ & 27 \\
\hline $\mathrm{T} 2 \mathrm{c}-\mathrm{T} 3$ & 14 \\
\hline \multicolumn{2}{|l|}{ Gleason score } \\
\hline Range (min-max) & $7-9$ \\
\hline $7, N$ & 3 \\
\hline $8, N$ & 33 \\
\hline$\geq 9, N$ & 6 \\
\hline \multicolumn{2}{|l|}{ Biopsy core positivity $(\%)$} \\
\hline Median & 50 \\
\hline Range (min-max) & $15-100$ \\
\hline \multicolumn{2}{|l|}{ Baseline PSA, ng/ml } \\
\hline Median & 10.45 \\
\hline Range (min-max) & $2.13-60$ \\
\hline IQR & 12.33 \\
\hline$<10, N$ & 10 \\
\hline$\geq 10$ but $<20, N$ & 18 \\
\hline$\geq 20, N$ & 13 \\
\hline \multicolumn{2}{|l|}{ Androgen suppression, mo } \\
\hline Median & 12 \\
\hline Range (min-max) & $12-24$ \\
\hline \multicolumn{2}{|l|}{ Recovery testosterone, mo } \\
\hline Median & 11.4 \\
\hline No recovery, $N(\%)$ & $3(7)$ \\
\hline \multicolumn{2}{|l|}{ Follow-up, mo } \\
\hline Median & 65.35 \\
\hline Range (min-max) & $6.05-92.68$ \\
\hline IQR & 20.57 \\
\hline With diabetes, $N(\%)$ & $5(12)$ \\
\hline With hypertension, $N(\%)$ & $22(54)$ \\
\hline With oral anti-coagulant, $N(\%)$ & $10(24)$ \\
\hline
\end{tabular}

$S D$ standard deviation, $I Q R$ interquartile range, $P S A$ prostate-specific antigen, ECOG Eastern Cooperative Oncology Group, $\mathrm{Yr}$ years, mo months, $N(\%)$ number of patients with percentages in parentheses

functions in competing risk data. Patients alive at the end of the study without having experienced relapse or late toxicity were censored, whereas those who died without relapse or late toxicity were counted as competing risk events. SAS $($ C software, version 9.4 (SAS institute, Inc., Cary, NC, USA) was employed to carry out all statistical analyses. $P$ values $<0.05$ denoted statistical significance.
Table 2 Acute and late toxicities

\begin{tabular}{lllll}
\hline Toxicity & Grade 1 & Grade 2 & Grade 3 & Total \\
& $N(\%)$ & $N(\%)$ & $N(\%)$ & $N(\%)$ \\
\hline Acute GI & $13(32)$ & $2(4)$ & 0 & $15(36)$ \\
Acute GU & $12(29)$ & $4(10)$ & 0 & $16(39)$ \\
Late GI & $6(14.63)$ & $1(2.44)$ & 0 & $7(17.07)$ \\
Late GU & $2(4.88)$ & $4(9.76)$ & 0 & $6(14.63)$ \\
Late rectal & $5(12.20)$ & 0 & 0 & $5(12.20)$ \\
\hline
\end{tabular}

GI gastrointestinal, $G U$ genitourinary

\section{Results}

Between March 2009 and 2012, 41 patients were enrolled. Patient characteristics are summarized in Table 1. Median age was 72 years (range, 51-81 years). All patients presented an Eastern Cooperative Oncology Group performance status 0 or 1 . Median pre-treatment PSA level and Gleason score were $10.5 \mathrm{ng} / \mathrm{mL}$ (range, $2.1-60 \mathrm{ng} / \mathrm{mL}$ ) and 8 (range, 7-9), respectively. Additionally, $12.2 \%$ of patients had diabetes, $24.4 \%$ were on anti-coagulant therapy and about one-half suffered from hypertension. All patients received ADT (luteinizing hormone-releasing hormone agonist only), which started 3-6 months before RT and continued for a total duration of $\geq 12$ months. Median duration of ADT was 12 months (range, 12-24 months).

The median time to testosterone recovery was 11.4 months after treatment with ADT, and $7.3 \%$ of the patients failed to normalize their testosterone.

Median follow-up duration was 65.35 months (range, 6.05-92.69 months).

The intended dose coverage was satisfied for all the PTVs and the near-maximum absorbed doses (D2\%) were within the acceptable limits.

Rectal mean dose value was 38.6 Gy (range, 33.2-42.6 Gy); mean values of V45, V50 were $26.9 \%$ (range, 20-31.8\%), 16.1\% (range, 11.4-20.7\%), respectively, with maximum dose values between 59.8 and $70.9 \mathrm{~Gy}$ (mean value, $66.3 \mathrm{~Gy}$ ). Bladder mean dose was $45.4 \mathrm{~Gy}$ (range, 40.6--53.6 Gy); mean values of V50, V60 were $26.1 \%$ (range, 11.7-55.8\%), 9.5\% (range, 2.3-19.4\%), respectively. Regarding the dose distribution received by the intestinal cavity, the mean value of the parameter V40 was $23.9 \%$ (range, $5.3-59 \%$ ) and the mean value of maximum dose was $49.1 \mathrm{~Gy}$ (range, 44.8-56.7 Gy). The mean penile bulb dose resulted $16.2 \mathrm{~Gy}$ (range, 4.7-52.8 Gy).

An example of the IMRT dose distribution (in sagittal and coronal reconstructed slices) is shown in the supplementary Fig. 1. 

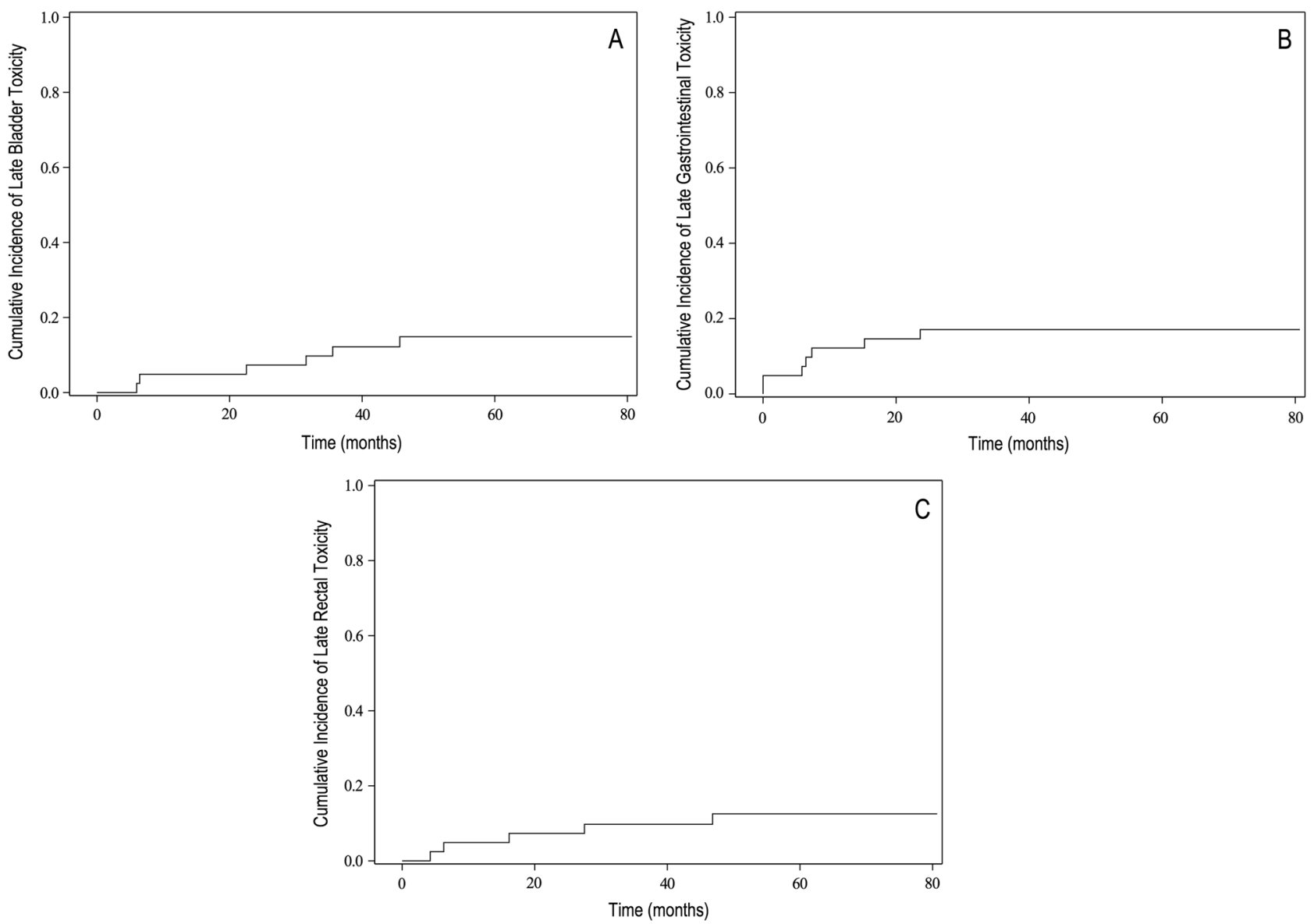

Fig. 1 Cumulative incidence curve for late bladder (a), gastrointestinal (b), and rectal (c) toxicity

\section{Toxicity data}

The number of patients with acute and late toxicities and their grades are listed in Table 2.

No severe toxicity was observed and in general, radiation therapy was well tolerated. Acute GI and GU toxicities of any grades were observed in 36 and $39 \%$ of patients. The only grade 2 GI toxicity was diarrhea requiring medication. The only acute grade $2 \mathrm{GU}$ toxicity was pollakiuria whose medication was necessary until the end of radiation therapy. None of the patients experienced grade 3 acute toxicity. The incidence rates of late GI and GU toxicity of any grade were $17.1 \%$ and $14.6 \%$, respectively. Concerning GI toxicity, the rate of late grade 2 was $2.4 \%$. None of the patients experienced late grade $\geq 2$ toxicity. GU toxicity rate of late grade 2 was $9.76 \%$ (Fig. 1). None of the patients presented grade $\geq 3$ late toxicity.

The results regarding the main predictors of late toxicity are shown in Tables 3 and 4. Between the clinical factors and the planning parameters, only the diabetes and the maximum of rectal dose distribution (D1\%) appeared to be statistically significant risk factors for the increase of probability of late rectal toxicity. All other risk factors were not statistically significant predictors for late toxicity.

\section{Efficacy data}

After a median follow-up of 56 months, two patients (4.9\%) experienced BR. Five-year BRFS was $95.1 \%$ (Fig. 2). Both patients had no radiologically documented local or regional recurrence, and received continuous ADT with a luteinizing hormone-releasing hormone agonist only. Three months after ADT, both patients achieved a PSA level of $\leq 1 \mathrm{ng} / \mathrm{ml}$.

\section{Discussion}

The Italian phase 3 trial on hypofractionation radiation therapy reported by Arcangeli et al. [23] showed a significant benefit of hypofractionation PORT in high-risk PCa patients. In such high-risk patients, there is still considerable controversy in the literature regarding the role of pelvic node irradiation. The rationale for pelvic irradiation is that a nontrivial proportion of clinically localized high-risk PCa 
Table $3 p$ value for each independent variable for late rectal toxicity with Gray's test and HR (95\% CI) and $p$ value with Fine and Gray modified Cox regression model

\begin{tabular}{|c|c|c|c|c|}
\hline \multirow[t]{2}{*}{ Outcome } & \multirow[t]{2}{*}{ IV } & \multirow{2}{*}{$\begin{array}{l}\text { Gray's test } \\
p\end{array}$} & \multicolumn{2}{|l|}{ Cox regression } \\
\hline & & & $\mathrm{HR}(95 \% \mathrm{CI})$ & $p$ \\
\hline Late rectal toxicity & Diabetes & 0.0398 & $5.89(1.07-32.58)$ & 0.042 \\
\hline Late rectal toxicity & Anti-coagulant therapy & 0.8515 & $0.81(0.09-7.45)$ & 0.85 \\
\hline Late rectal toxicity & Hypertension & 0.5344 & $0.57(0.10-3.30)$ & 0.53 \\
\hline Late rectal toxicity & ADT duration & $0.3296^{\mathrm{a}}$ & $1.09(0.93-1.28)$ & 0.28 \\
\hline
\end{tabular}

$I V$ indipendent variable

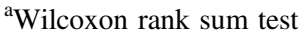

Table $4 p$ value for each independent dosimetric variable for late toxicity

\begin{tabular}{llll}
\hline Outcome & IV & \multicolumn{2}{l}{ Cox regression } \\
\cline { 3 - 4 } & & $p$ & HR $(95 \% \mathrm{CI})$ \\
\hline Bladder toxicity & $\mathrm{V} 50$ & 0.95 & $1.00(0.94-1.07)$ \\
Bladder toxicity & $\mathrm{V} 60$ & 0.48 & $1.08(0.88-1.33)$ \\
Rectal toxicity & $\mathrm{V} 45$ & 0.26 & $1.16(0.89-1.50)$ \\
Rectal toxicity & $\mathrm{V} 50$ & 0.28 & $1.18(0.88-1.58)$ \\
Rectal toxicity & $\mathrm{D}_{1 \%}$ & 0.024 & $1.43(1.05-1.95)$ \\
Rectal toxicity & $\mathrm{D}_{1 \%}$ & 0.07 & $5.00(0.89-28.19)$ \\
& $\mathrm{Diabetes}^{\mathrm{a}}$ & 0.035 & $1.36(1.02-1.82)$ \\
Gastrointestinal toxicity & $\mathrm{V} 40$ & 0.42 & $1.06(0.92-1.20)$ \\
Gastrointestinal toxicity & $\mathrm{D}_{1 \%}$ & 0.54 & $1.28(0.80-1.61)$ \\
Bulb toxicity & Dmean & $0.96^{\mathrm{b}}$ & \\
\hline
\end{tabular}

$I V$ independent variable

${ }^{a}$ MVA Fine and Gray modified Cox regression model

${ }^{b}$ Wilcoxon rank sum test

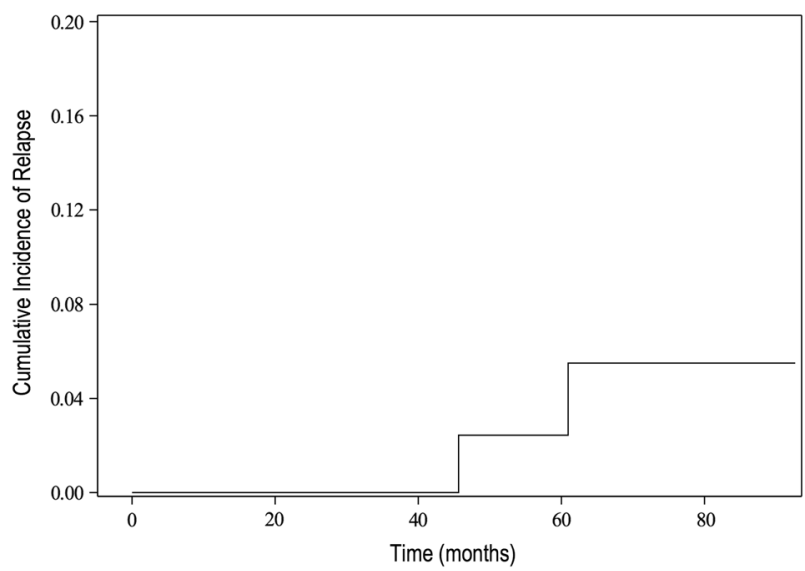

Fig. 2 Cumulative incidence curve for biochemical relapse (Cox regression model)

patients have micrometastatic nodal disease that is not otherwise apparent [17].

The RTOG 94-13 study [24-26] included patients with an estimated $\geq 15 \%$ chance of $L N$ involvement based on the
Roach formula [17]. In this study, patients were randomized to PORT or WPRT. Patients were also randomized to total 4 months of neoadjuvant and concurrent ADT or 4 months of adjuvant ADT. In patients treated with neoadjuvant/ concurrent ADT, the use of WPRT improved progressionfree survival as well as biochemical control. However, in patients treated with adjuvant ADT, outcomes were equivalent irrespective of ADT timing. In order to address the remaining questions, RTOG 09-24 is currently accruing patients to further examine the impact of pelvic nodal radiation in a two-arm design. These patients will be treated by current standards, with high-dose radiation ( $45 \mathrm{~Gy}$ to the pelvis followed by boost to the prostate to $79.2 \mathrm{~Gy}$ ) as well as long-term ADT (32 months).

GETUG-01 was a French randomized trial that did not show a benefit in overall survival or progression-free survival with WPRT, though the radiation dose (mean total dose of $68 \mathrm{~Gy}$ ) was low by modern standards [27]. In contrast, Aizer et al. retrospectively demonstrated significant improvement in biochemical control with pelvic RT with use of higher dose (mean 75.6 Gy); however, longer follow-up is needed [28]. A recent National Cancer Data Base analysis [29] of more than 14,000 high-risk patients suggested that there was no overall survival advantage with WPRT compared to PORT, though there are inherent limitations to such a retrospective analysis.

Our study was designed when little literature data was available on toxicity and efficacy of complete pelvic irradiation (i.e., iliac nodes included).

Our results seem to show a good tolerability. The lower rates of side effects that we observed, compared to the prospective studies reporting late toxicity of prostate hypofractionation combined with WPRT [30-32] were likely attributed to the robustness of our planning (in terms of severe DVH constraints for OARs and quality of dose distribution), to an accurate daily preparation phase of the patients to minimize the impact of the organ movement and to permit a reliable on-line IGRT strategy.

Concerning the secondary end point, the good results compared to the prospective studies regarding high-risk 
prostate patients treated with ADT and IMRT-SIB [30-32] might have been related to the adequacy of pelvic LN coverage, as explained by Spratt et al. [4]. Although encouraging results need to be interpreted with caution due to the design of our investigation.

Our study has some shortcomings. First is the delivery technique.

An unquestioned beneficial of volumetric-modulated arc therapy (VMAT) over fixed-gantry IMRT is represented by the greater efficiency of delivery [33-36]. In fact, the shorter treatment delivery time could minimize intrafraction organ motion impact $[37,38]$. Whereas the potential of the delivery efficiency and the comparable plan quality with regard to the static IMRT, VMAT may be considered the elective technique for WPRT.

Second is the IGRT strategy itself. As a matter of fact, to estimate the prostate motion relative to the pelvic bone, a two-step image registration is necessary, implying the acquisition of a cone beam CT (CBCT) prior to each treatment. This technology was implemented later in our Institute, so we could apply the more adequate dual registration strategy starting from 2013 onward. Finally, the RTOG alone may not be an adequate way to evaluate toxicity patient, with a validated instrument for patientreported outcomes is preferable.

A more comprehensive measurement system may be able to assess more subtle but still clinically relevant morbidity associated with each treatment [39].

\section{Conclusions}

We reported the toxicity and efficacy results of a phase II trial regarding the high-risk prostate cancer patients treatment paradigm combining dose hypofractionation, irradiation of pelvic nodes (common iliac nodes included), and concurrent ADT. Overall, low level of toxicities and good effectiveness were measured.

This treatment strategy may merit further investigation in a phase III randomized trial to confirm its safe efficacy and effectively.

\section{Compliance with ethical standards}

Conflict of interest The authors declare that they have no conflict of interest.

Open Access This article is licensed under a Creative Commons Attribution 4.0 International License, which permits use, sharing, adaptation, distribution and reproduction in any medium or format, as long as you give appropriate credit to the original author(s) and the source, provide a link to the Creative Commons license, and indicate if changes were made. The images or other third party material in this article are included in the article's Creative Commons license, unless indicated otherwise in a credit line to the material. If material is not included in the article's Creative Commons license and your intended use is not permitted by statutory regulation or exceeds the permitted use, you will need to obtain permission directly from the copyright holder. To view a copy of this license, visit http://creativecommons. org/licenses/by/4.0/.

\section{References}

1. Walz J, Joniau S, Chun FK, Isbarn H, Jeldres C, Yossepowitch O, et al. Pathological results and rates of treatment failure in high-risk prostate cancer patients after radical prostatectomy. BJU Int. 2011;107:765-70.

2. Horwitz EM, Bae K, Hanks GE, Porter A, Grignon DJ, Brereton $\mathrm{HD}$, et al. Ten-year follow-up of radiation therapy oncology group protocol 92-02: a phase III trial of the duration of elective androgen deprivation in locally advanced prostate cancer. J Clin Oncol. 2008;26:2497-504.

3. Roach M III, DeSilvio M, Valicenti R, Grignon D, Asbell SO, Lawton C, et al. Whole-pelvis, "mini-pelvis," or prostate-only external beam radiotherapy after neoadjuvant and concurrent hormonal therapy in patients treated in the Radiation Therapy Oncology Group 9413 trial. Int J Radiat Oncol Biol Phys. 2006;66:647-53.

4. Spratt DE, Vargas HA, Zumsteg ZS, Golia Pernicka JS, Osborne JR, Pei X, Zelefsky MJ, et al. Patterns of lymph node failure after dose-escalated radiotherapy: implications for extended pelvic lymph node coverage. Eur Urol. 2017;71:37-43.

5. Perez CA, Lee HK, Georgiou A, Lockett MA. Technical factors affecting morbidity in definitive irradiation for localized carcinoma of the prostate. Int $\mathrm{J}$ Radiat Oncol Biol Phys. 1994;28:811-9.

6. Mameghan H, Fisher R, Mameghan J, Watt WH, Tynan A. Bowel complications after radiotherapy for carcinoma of the prostate: the volume effect. Int J Radiat Oncol Biol Phys. 1990;18:315-20.

7. Nutting CM, Convery DJ, Cosgrove VP, Rowbottom C, Padhani AR, Webb S, Dearnaley DP, et al. Reduction of small and large bowel irradiation using an optimized intensity-modulated pelvic radiotherapy technique in patients with prostate cancer. Int $\mathbf{J}$ Radiat Oncol Biol Phys. 2000;48:649-56.

8. Luxton G, Hancock SL, Boyer AL. Dosimetry and radiobiologic model comparison of IMRT and 3D conformal radiotherapy in treatment of carcinoma of the prostate. Int J Radiat Oncol Biol Phys. 2004;59:267-84.

9. Cavey ML, Bayouth JE, Colman M, Endres EJ, Sanguineti G, et al. IMRT to escalate the dose to the prostate while treating the pelvic nodes. Strahlenther Onkol. 2005;181:431-41.

10. Ashman JB, Zelefsky MJ, Hunt MS, Leibel SA, Fuks Z. Whole pelvic radiotherapy for prostate cancer using $3 \mathrm{D}$ conformal and intensity-modulated radiotherapy. Int J Radiat Oncol Biol Phys. 2005;63:765-71.

11. Jani AB, Su A, Milano MT. Intensity-modulated versus conventional pelvic radiotherapy for prostate cancer: analysis of acute toxicity. Urology. 2006;67:147-51.

12. Kuban DA, Tucker SL, Dong L, et al. Long-term results of the M. D. Anderson randomized dose-escalation trial for prostate cancer. Int J Radiat Oncol Biol Phys. 2008;70:67-74.

13. Zietman AL, DeSilvio ML, Slater JD, Starkschall G, Huang EH, Cheung MR, et al. Comparison of conventional-dose vs high-dose conformal radiation therapy in clinically localized adenocarcinoma of the prostate: a randomized controlled trial. JAMA. 2005;294:1233-9.

14. Brenner DJ, Marinez AA, Edmundson GK, Mitchell C, Thames HD, Armour EP. Direct evidence that prostate tumors show high sensitivity to fractionation (low alpha/beta ratio), similar to late- 
responding normal tissue. Int $\mathrm{J}$ Radiat Oncol Biol Phys. 2002;52:6-13.

15. Brenner DJ, Hall EJ. Fractionation and protraction for radiotherapy of prostate carcinoma. Int J Radiat Oncol Biol Phys. 1999;43:1095-101.

16. Cooperberg MR, Pasta DJ, Elkin EP, Litwin MS, Latini DM, Du Chane J, et al. The University of California, San Francisco Cancer of the Prostate Risk Assessment score: a straightforward and reliable preoperative predictor of disease recurrence after radical prostatectomy. J Urol. 2006;175:2369.

17. Roach M, Marquez C, You H, Narayan P, Coleman L, Nseyo UO, et al. Predicting the risk of lymph node involvement using the pretreatment prostate specific antigen and Gleason score in men with clinically localized prostate cancer. Int J Radiat Oncol Biol Phys. 1993;28:33-37.

18. Lawton CA, Michalski J, El-Naqa I, Buyyounouski MK, Lee WR, Menard C, et al. RTOG GU radiation oncology specialists reach consensus on pelvic lymph node volumes for high-risk prostate cancer. Int J Radiat Oncol Biol Phys. 2009;74:383-38.

19. Roach M III, Hanks G, Thames H Jr, Schellhammer P, Shipley WU, Sokol GH, et al. Defining biochemical failure following radiotherapy with or without hormonal therapy in men with clinically localized prostate cancer. Recommendations of the RTOG-ASTRO phoenix consensus conference. Int J Radiat Oncol Biol Phys. 2006;65:965-74.

20. Simon R. Optimal two-stage designs for phase II clinical trials. Control Clin Trials. 1989;10:1-10. https://doi.org/10.1016/01972456(89)90015-9.

21. Fine JP, Gray RJ. A proportional hazards model for the subdistribution of a competing risk. J Am Stat Assoc. 1999;94:496-509.

22. Gray RJ. A class of K-sample tests for comparing the cumulative incidence of a competing risk. Ann Stat. 1988;16:1141-54.

23. Arcangeli G, Saracino B, Gomellini S, Petrongari MG, Arcangeli $\mathrm{S}$, Sentinelli S, et al. A prospective phase III randomized trial of hypofractionation versus conventional fractionationin patients with high-risk prostate cancer. Int J Radiat Oncol Biol Phys. 2010;78:11-18.

24. Roach M III, DeSilvio M, Lawton CA, Uhl V, Machtay M, Seider $\mathrm{MJ}$, et al. Phase III trial comparing whole-pelvic versus prostateonly radiotherapy and neoadjuvant versus adjuvant combined androgen suppression: Radiation Therapy Oncology Group 9413. J Clin Oncol. 2003;21:1904-11.

25. Lawton CA, DeSilvio M, Roach M III, Uhl V, Kirsch R, Seider $\mathrm{M}$, et al. An update of the phase III trial comparing whole pelvic to prostate only radiotherapy and neoadjuvant to adjuvant total androgen suppression: updated analysis of RTOG 94-13, with emphasis on unexpected hormone/radiation interactions. Int $\mathbf{J}$ Radiat Oncol Biol Phys. 2007;69:646-55.

26. Roach M III, Hunt D, Lawton CA, Hsu IC, Lusting RA, Seider M, et al. Radiation Therapy Oncology Group (RTOG) 9413: a randomized trial comparing whole pelvic radiation therapy (WPRT) to prostate only (PORT) and neoadjuvant hormonal therapy (NHT) to adjuvant hormonal therapy (AHT). Int J Radiat Oncol Biol Phys. 2013;2:S106-S107.

27. Pommier P, Chabaud S, Lagrange JL, Richaud P, Le Prise E, Wagner JP, et al. Is there a role for pelvic irradiation in localized prostate adenocarcinoma? update of the long-term survival results of the GETUG-01 randomized study. Int J Radiat Oncol Biol Phys. 2016;96:759-69.

28. Aizer AA, Yu JB, McKeon AM, Decker RH, Colberg JW, Peschel RE. Whole pelvic radiotherapy versus prostate only radiotherapy in the management of locally advanced or aggressive prostate adenocarcinoma. Int J Radiat Oncol Biol Phys. 2009;75(no. 5):1344-9.

29. Amini A, Jones BL, Yeh N, Rusthoven CG, Armstrong $\mathrm{H}$, Kavanagh BD. Survival outcomes of whole-pelvic versus prostate-only radiation therapy for high-risk prostate cancer patients with use of the national cancer data base. Int J Radiat Oncol Biol Phys. 2015;93:1052-63.

30. McCammon R, Rusthoven KE, Kavanagh B, Newell S, Newman F, Raben D. Toxicity assessment of pelvic intensity-modulated radiotherapy with hypofractionated simultaneous integrated boost to prostate for intermediate- and high-risk prostate cancer. Int $\mathrm{J}$ Radiat Oncol Biol Phys. 2009;75:413-20.

31. Adkison JB, McHaffie DR, Bentzen SM, Patel RR, Khuntia D, Petereit DG, et al. Phase I trial of pelvic nodal dose escalation with hypofractionated IMRT for high-risk prostate cancer. Int J Radiat Oncol Biol Phys. 2012;82:184-90.

32. Quon H, Cheung PC, Loblaw DA, Morton G, Pang G, Szumacher $\mathrm{E}$, et al. Hypofractionated concomitant intensity-modulated radiotherapy boost for high-risk prostate cancer: late toxicity. Int J Radiat Oncol Biol Phys. 2012;82:898-905.

33. Yoo S, Wu J, Lee R, Yin FF. Radiotherapy treatment plans with rapid arc for prostate cancer involving seminal vesicles and lymph nodes. Int J Radiat Oncol Biol Phys. 2010;76:935-42.

34. Davidson MTM, Blake S, Batchelar DL, Cheung P, Mah K. Assessing the role of volumetric modulated arc therapy (VMAT) relative to IMRT and helical tomotherapy in the management of localized, locally advanced, and post-operative prostate cancer. Int J Radiat Oncol Biol Phys. 2011;80:1550-8.

35. Myerhaug S, Chan G, Graig T, Weinberg V, Cheng C, Roach M. A treatment planning and acute toxicity comparison of two pelvic nodal volume delineation techniques and delivery comparison of intensity-modulated radiotherapy versus volumetric modulated arc therapy for hypofractionated high-risk prostate cancer radiotherapy. Int J Radiat Oncol Biol Phys. 2012;82:e657-62.

36. Fontenot JD, King ML, Johnson SA, Wood CG, Price MJ, Lo KK. Single-arc volumetric-modulated arc therapy can provide dose distributions equivalent to fixed-beam intensity-modulated radiation therapy for prostatic irradiation with seminal vesicle and/ or lymph node involvement. Br J Radiol. 2012;85:231-6.

37. Langen KM, Willoughby TR, Meeks SL, Santhanam A, Cunningham $\mathrm{A}$, Levine $\mathrm{L}$, et al. Observations on real-time prostate gland motion using electromagnetic tracking. Int J Radiat Oncol Biol Phys. 2008;71:1084-90.

38. Li JS, Lin MH, Buyyounouski MK, Horwitz EM, Ma CM. Reduction of prostate intrafractional motion from shortening the treatment time. Phys Med Biol. 2013;58:4921-32.

39. Wei JT, Dunn RL, Litwin MS, Sandler HM, Sanda MG. Development and validation of the expanded prostate cancer index composite (EPIC) for comprehensive assessment of health-related quality of life in men with prostate cancer. Urology. 2000;56:899-905. 